\title{
Antibacterial Activity of Bangladeshi Raw and Commercial Honey Against Staphylococcus aureus
}

\author{
Abhinandan Chowdhury*, Sohidul Islam \& Ramen Chowdhury \\ Department of Biochemistry \& Microbiology, North South University,Bangladesh
}

Received Date: June 08, 2018; Published Date: July 18, 2018

*Corresponding author: Abhinandan Chowdhury, North South University, Bashundhara, Dhaka 1229, Bangladesh. Tel: +880-2-55668200; Email: abhinandan.chowdhury@northsouth.edu

\begin{abstract}
Honey has been used as antibacterial agent since ages in the Asian countries. Though many studies have been done on this antimicrobial property of honey, studies on Bangladeshi honey related to such property are rare. Therefore, this study investigates the antibacterial spectrum of raw honey (collected from Sundarbans) and commercial honey from Bangladesh against ten strains of Staphylococcus aureus including multidrug resistant Staphylococcus aureus. Disk Diffusion method was performed to determine the zone of inhibition of honey as well as antibiotics against each Staphylococcus aureus strains. The zone of inhibitionfor different concentration ofhoney $(25 \%, 50 \%, 75 \%$ and $100 \%$ v $/ v)$ were between 7 to $12 \mathrm{~mm}$. Out often strains, seven exhibited sensitivity to honey and three exhibited resistance. It was also observed that the sensitivity of bacteria to antibiotic (methicillin) increased when antibiotic discs were soaked in honey. Furthermore, it was also found that raw honey (ZOI, $12 \mathrm{~mm}$ max.) is more effective than commercial honey (ZOI, 9-10 mm max.) when it comes to inhibiting Staphylococcus aureus. These results indicate that Bangladeshi honey especially raw honey can be used for better treatment of Staphylococcus aureus infections along with antibiotic.
\end{abstract}

Keywords: Honey; Bangladesh; Antibacterial; Staphylococcus aureus;Multidrug resistant

\section{Introduction}

Since the ancient times, honey has been used for both nutritional and therapeutic purposes. However, in the primordial application of honey as a medication, there was no understanding of it having antibacterial properties.Recently, many researchers have reported about broad-spectrum antibacterial activity of honey against various bacterial species. Studies found that honey works well against almost sixty species of bacteria including aerobes and anaerobes as well as grampositives and gram-negatives $[1,2]$. This remarkable attribute of honey has been proved to be derived from multiple factors, such as high sugar content, low water content, methylglyoxal, low $\mathrm{pH}$, hydrogen peroxide, bee defensin-1, natural flora and phytochemicals [3]. Moreover, studies have shown that honey hinders the development of biofilms as well as suspend quorum sensing, which diminishes bacterial virulence. Hence, making the bacteria more sensitive to traditional antibiotics which have lost their potency. [4-12].

One of the concerning issues, considering the antibiotic resistant bacteria, is the rise of methicillin-resistant $S$. aureus (MRSA) which is a worldwide problem especially in developing countries like Bangladesh [13]. Staphylococcus aureus (S. aureus) is frequently found in the nose, respiratory tract, and on the skin and they do not always cause diseases. Nonetheless, pathogenic strains often promote infections by producing potent protein toxins and expressing cell-surface proteins that bind and inactivate antibodies [14]. The evolution of antibiotic resistance does not cause the organism to be more intrinsically virulent than strains of $S$. aureus that have no antibiotic resistance, but resistance does make $S$. aureus infection more difficult to treat with standard types of antibiotics and thus more dangerous [15].The current situation extremely demands the development of unique antibacterial agents, which provides an opportunity for honey to be re-established as a broad-spectrum antibacterial agent that has less or almost no side effects, and is non-toxic to human tissue. Though honey had been used for treating bacterial infections in Bangladesh, but rarely any studies had been performed on the antibacterial spectrum of Bangladeshi honey.

Therefore, the focus of this research was to report on antibacterial spectrum of Bangladeshi honey against ten strains of $S$. aureus including MRSA. Moreover, the antibacterial efficacy of commercial honeys found in local markets were also investigated and compared with raw honey. 


\section{Methodology}

\section{Honey sample}

Raw honey sample from Sundarban, Bangladesh and two others were commercial honey (named C1 and C2), which were produced and manufactured in Bangladesh were selected for the experiment.

\section{Bacterial sample}

The antibacterial properties of three different honey samples were tested against ten Staphylococcus aureusisolates. Six of them were isolated from clinical samples and four were isolated from environmental samples (Table 1).

Table 1: List of Staphylococcus aureus isolatesused in this research and their sources.

\begin{tabular}{|c|c|c|c|}
\hline $\begin{array}{l}\text { Sample } \\
\text { ID }\end{array}$ & LAB ID & Sample Source & \multirow{7}{*}{ Clinical Sample } \\
\hline 1 & IIB & Urine of heart patient & \\
\hline 2 & IIIB & Urine of heart patient & \\
\hline 3 & VIIIB & Urine of heart patient & \\
\hline 4 & 845 & Pus (Ibn sina hospital) & \\
\hline 5 & 550 & Pus (Ibn sina hospital) & \\
\hline 6 & 599 & Urine (Ibn sina hospital) & \\
\hline 7 & EF 1 & $\begin{array}{l}\text { Waste water (Bashundhara } \\
\text { eye hospital) }\end{array}$ & \multirow{4}{*}{$\begin{array}{l}\text { Environmental } \\
\text { Sample }\end{array}$} \\
\hline 8 & EF 2 & $\begin{array}{l}\text { Waste water (Bashundhara } \\
\text { eye hospital) }\end{array}$ & \\
\hline 9 & AM 1 & Waste water (Apollo hospital) & \\
\hline 10 & AM 2 & Waste water (Apollo hospital) & \\
\hline
\end{tabular}

\section{Antibiotic}

Ten antibiotics i.e. ampicillin, cefotaxime, doxycycline, erythromycin, gentamicin, imipenem, levofloxacin, methicillin, tetracycline and tobramycin were used for susceptibility testing.

\section{Media preparation}

Mannitol salt agar (Oxoid, Product ID\# CM0085) and Mueller-Hinton agar (Oxoid, Product ID\# CM0337) was prepared according to standard procedure [16,17]. Phosphate Buffer Saline (PBS) was prepared comprised of the following: 8 $\mathrm{g}$ of $\mathrm{NaCl}, 0.2 \mathrm{~g}$ of KCl, $1.44 \mathrm{~g}$ of Na2HPO 4 and $0.24 \mathrm{~g}$ of KH2PO4. These amounts were added to the required volume of distilled water (1 liter). The $\mathrm{pH}$ was adjusted to 7.4 with $\mathrm{HCl}$ and then autoclaved [18].

\section{Isolation and identification of Staphylococcus aureus}

For all the ten $S$. aureus strains, a tenfold serial dilution in PBS was performed. $100 \mu \mathrm{l}$ of bacterial suspension was placed in the center of the Mannitol Salt Agar (MSA) plate using pipette. The sample was spread evenly over the surface of agar using the sterile cotton swab. All the plates were then incubated at $37^{\circ} \mathrm{C}$ for 24 hours. Several Staphylococcus species other than
S. aureus are mannitol positive and produce yellow colonies surrounded by yellow zones on this medium (e.g. S. capitis, S. xylosus, S. cohnii, S. sciuri, S. simulans, and other species) [19]. Therefore, further biochemical tests were performed for the identification of $S$. aureus such as, catalase and coagulase test. After biochemical identification, S. aureus isolated were subcultured on MSA plate for later use.

\section{Disc diffusion test}

Bacterial suspensions were prepared in PBS from fresh culture of $S$. aureus. The suspensions were adjusted to 2 McFarland standard. 2 McFarland standard was prepared by mixing $0.2 \mathrm{ml}$ of $1.0 \%$ barium chloride dihydrate $\left(\mathrm{BaCl}_{2} \cdot 2 \mathrm{H}_{2} \mathrm{O}\right)$, with $9.8 \mathrm{ml}$ of $1 \%$ sulfuric acid $\left(\mathrm{H}_{2} \mathrm{SO}_{4}\right)$ [20]. Muller Hinton agar plates were inoculated by immersing sterile cotton swabs in $100 \mu \mathrm{l}$ bacterial suspensions on entire surface of the plate. $5 \mathrm{~mm}$ diameter discs were cut from filter paper using punch machine and autoclaved. Different concentrations $(25 \%, 50 \%, 75 \%$ and $100 \% \mathrm{v} / \mathrm{v}$ ) of all three honey samples were prepared and the discs were soaked in it. The discs were then applied on the inoculated agar plate. Plates containing the discs were incubated at $37^{\circ} \mathrm{C}$ for $24 \mathrm{~h}$. Zones of inhibition were measured by using ruler and the diameter ofzones was recorded.

To compare efficacy between methicillin and methicillin soaked in honey, similar procedure was followed. Methicillin discs were soaked in $100 \%$ honey sample and were put on inoculated agar plates. Plates were incubated at $37^{\circ} \mathrm{C}$ for $24 \mathrm{~h}$. The zone of inhibition of methicillin discs containing honey were measured and compared with zone of inhibition of methicillin discs.

Antibiotic susceptibility tests were also performed by the Kirby-Bauer method [17]. The antibiotic discs were applied directly on the inoculated plate to find out antibiotic susceptibility of the isolates. All the plates were incubated at $37^{\circ} \mathrm{C}$ for $24 \mathrm{~h}$. Zone of inhibition was measured by using ruler and the diameter of zones was recorded.

\section{Results}

\section{Antibiotic resistance profile of the isolates}

From the antibiotic susceptibility testing it was found that, among ten $S$. aureus strains, five were resistant and five were intermediate susceptible to methicillin and erythromycin (Table 2). All the strains were resistant to ampicillin and nine were cefotaxime resistant. Most of the strains showed sensitivity towards doxycycline, gentamicin, imipenem, levofloxacine, tetracycline and tobramycin. The strain S. aureus 599 showed resistance to six antibiotics and intermediate susceptible to two antibiotics. All the test organisms were multidrug resistant. No single strain showed resistance to tobramycin.

\section{Synergistic effect of methicillin and honey}

For this test, antibacterial effect of methicillin discs were compared with methicillin discs soaked in honey (Figure 1). 
Among ten $S$. aureus strains, three strains were not susceptible to honey soaked methicillin discs, which were EF 1 , AM 1 and AM 2. For rest of the isolates, honey soaked methicillin discs exhibited greater zone of inhibition than methicillin discs alone. Furthermore, raw honey soaked methicillin showed greater zone of inhibition than $\mathrm{C} 1$ honey soaked methicillin or C2 honey soaked methicillin discs. One of the strains, S. aureus 599, which was resistant to six antibiotics including methicillin, showed greater zone of inhibition in presence of both raw and commercial honey-soaked methicillin.

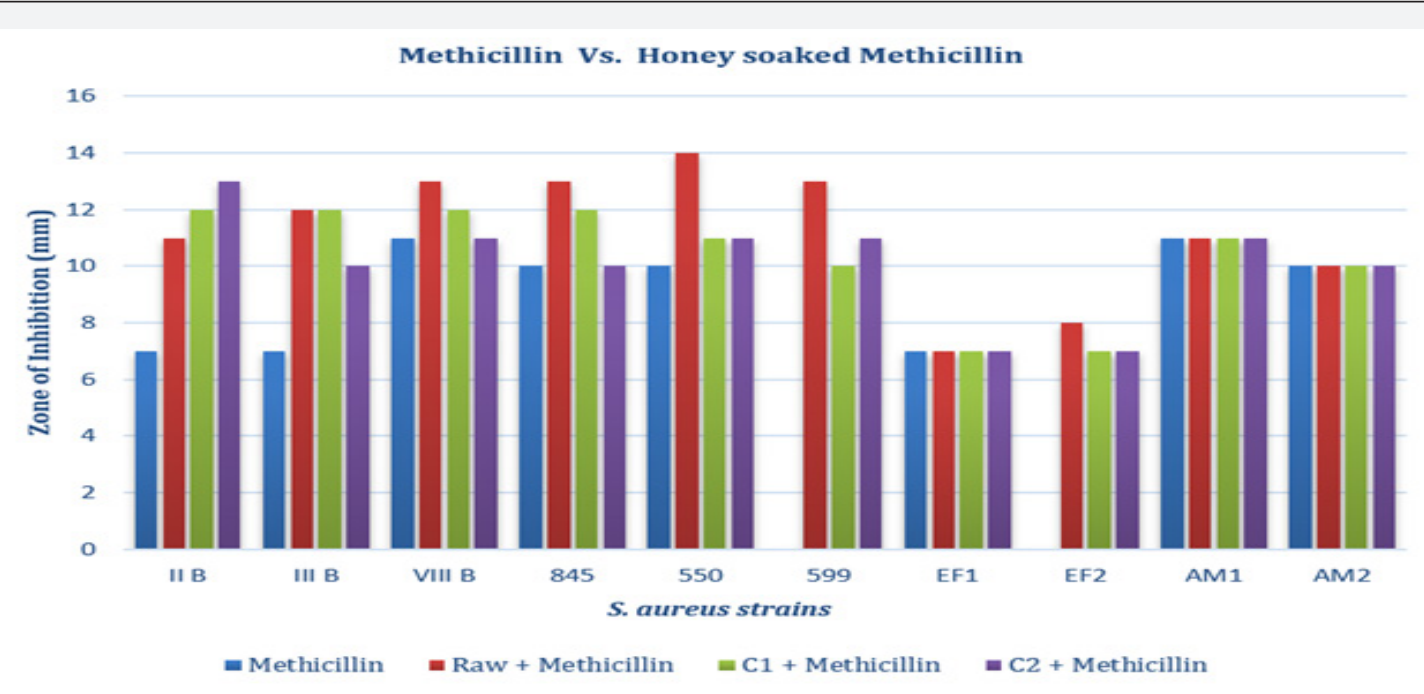

Figure 1: Methicillin vs. honey containing methicillin: A comparative graph.

\section{Susceptibility profile against different concentrations of honey}

The strains, EF1, AM1 and AM2 were not susceptible to any concentration of three different types of honey samples (Figure 2). Strain III B showed no inhibition at $25 \%$ concentration of raw honey and $25 \%, 50 \%$ and $75 \% \mathrm{v} / \mathrm{v}$ concentration of C2 honey. Similarly, strain VIII B showed no zone of inhibition at 25\%, 50\% and $75 \% \mathrm{v} / \mathrm{v}$ concentration of C1 honey. The strains 845 and
550 showed no inhibition at $25 \%$ concentration of C1 honey. At $25 \% \mathrm{v} / \mathrm{v}$ concentration of $\mathrm{C} 2$ honey, no inhibition zone was seen by strain 845 and 599. Also, EF 2 showed no zone of inhibition at $25 \% \mathrm{v} / \mathrm{v}$ concentration of raw, C1 and C2 honey.The highest zone of inhibition was shown by raw honey against strains 845 and 550 which was $12 \mathrm{~mm}$ while the lowest zone of inhibition was $7 \mathrm{~mm}$. The highest zone of inhibition exhibited by C1 and C2 honeys was $10 \mathrm{~mm}$.

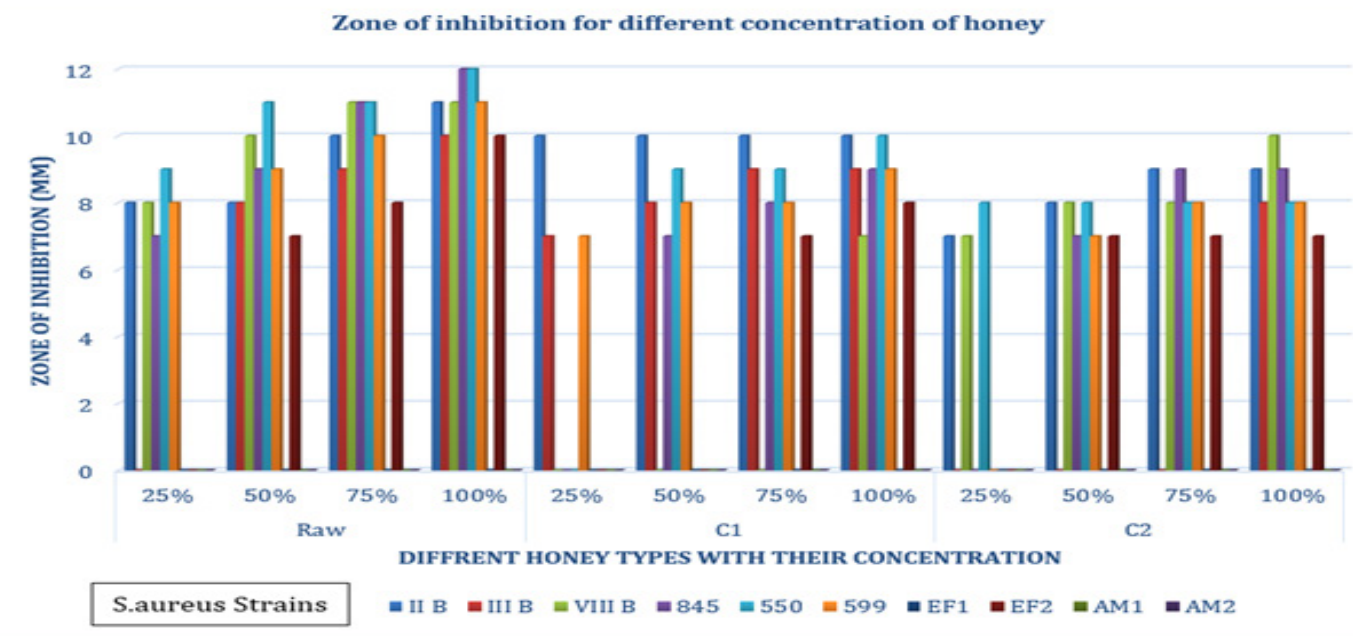

Figure 2: Graph showing zone of inhibition for different concentration of honey against $S$. aureus strains.

\section{Discussion}

Previous research showed that Manuka honey (from the tree Leptospermum scoparium, found in Australia and New Zealand) can inhibit growth of methicillin-resistant Staphylococcus aureus(MRSA) [3,4,21-23]. This study was undertaken to investigate the antibacterial activity of Bangladeshi honey. Three 


\section{Novel Approaches in Drug Designing \& Development}

different types of honey were used in this study. One of them was raw honey collected from Sundarban, Khulna and other two were commercially produced honey in Bangladesh obtained from local market. These honey samples were tested against certain Staphylococcus aureus isolates. All the Staphylococcus aureus strains used in this experiment were found out to be multidrug resistant. Most of the strains showed resistance to ampicillin, cefotaxime, erythromycin and methicillin (Table 2).

Table 2: Antibiotic susceptibility pattern of ten different Staphylococcus aureus isolates (R- Resistant, I.S.- Intermediate susceptible, SSusceptible.

\begin{tabular}{|c|c|c|c|c|c|c|c|c|c|c|}
\hline \multirow{2}{*}{ Antibiotics } & \multicolumn{10}{|c|}{ Staphylococcus aureus strains } \\
\hline & II B & III B & VIII B & 845 & 550 & 599 & EF 1 & EF 2 & AM 1 & AM 2 \\
\hline Ampicillin & $\mathrm{R}$ & $\mathrm{R}$ & $\mathrm{R}$ & $\mathrm{R}$ & $\mathrm{R}$ & $\mathrm{R}$ & $\mathrm{R}$ & $\mathrm{R}$ & $\mathrm{R}$ & $\mathrm{R}$ \\
\hline Cefotaxime & $\mathrm{R}$ & $\mathrm{R}$ & $\mathrm{R}$ & $\mathrm{R}$ & $\mathrm{R}$ & I.S. & $\mathrm{R}$ & $\mathrm{R}$ & $\mathrm{R}$ & $\mathrm{R}$ \\
\hline Doxycycline & S & $S$ & S & $\mathrm{S}$ & S & $\mathrm{R}$ & $\mathrm{S}$ & $S$ & $\mathrm{~S}$ & $S$ \\
\hline Erythromycin & $\mathrm{R}$ & $\mathrm{R}$ & $\mathrm{R}$ & I.S. & $\mathrm{R}$ & $\mathrm{R}$ & I.S. & I.S. & I.S. & I.S. \\
\hline Gentamicin & S & $S$ & S & S & S & I.S. & $S$ & $S$ & S & S \\
\hline Imipenem & $\mathrm{S}$ & $\mathrm{S}$ & $\mathrm{S}$ & $\mathrm{S}$ & $\mathrm{S}$ & $\mathrm{R}$ & $\mathrm{S}$ & $\mathrm{S}$ & $\mathrm{S}$ & $\mathrm{S}$ \\
\hline Levofloxacin & S & S & S & $\mathrm{R}$ & $\mathrm{R}$ & $\mathrm{S}$ & S & $S$ & S & S \\
\hline Methicillin & $\mathrm{R}$ & $\mathrm{R}$ & I.S. & I.S. & I.S. & $\mathrm{R}$ & $\mathrm{R}$ & $\mathrm{R}$ & I.S. & I.S. \\
\hline Tetracycline & $S$ & $S$ & $S$ & $\mathrm{~S}$ & $\mathrm{~S}$ & $\mathrm{R}$ & $\mathrm{S}$ & $\mathrm{S}$ & S & $S$ \\
\hline Tobramycin & $\mathrm{s}$ & $\mathrm{s}$ & $\mathrm{S}$ & $\mathrm{S}$ & $\mathrm{S}$ & $\mathrm{s}$ & $\mathrm{S}$ & $\mathrm{S}$ & $\mathrm{S}$ & $\mathrm{s}$ \\
\hline
\end{tabular}

From the observed data, it was found that Bangladeshi honey (both raw and commercial) not only showed bactericidal effect to methicillin resistant Staphylococcus aureus but also showed inhibitory effect to multidrug resistant Staphylococcus aureus. However, three among ten $S$. aureus strains used in this study exhibited resistance to honey. The antibacterial activity of honey is highly variable and can be changed over time. Even, honeys produced in one location at one time could vary in antibacterial activity [24]. It was prominent from our result that at $100 \%$ concentration all three honey samples showed maximum inhibitions and the bactericidal effect decreased when the concentrations of honey were reduced. However, honey could still retain its bactericidal activity at $50 \% \mathrm{v} / \mathrm{v}$ and $75 \% \mathrm{v} / \mathrm{v}$ concentration. Yet considerable amount of inhibition to most of the isolates was noticed even at $25 \% \mathrm{v} / \mathrm{v}$.

Previously some researchers demonstrated that at low concentration such as $25 \% \mathrm{v} / \mathrm{v}$ concentration of Costa Rican honey can inhibit Staphylococcus aureus growth [25]. Present study showed that not all study strains of Staphylococcus aureus were sensitive to $25 \% \mathrm{v} / \mathrm{v}$ concentration of Bangladeshi honey samples. The possible reason could be the variation of antibacterial factors present in honey region to region. Another reason could be, not all bacterial strains of similar species show sensitivity or resistance in similar manner. A previous study reported that medical-grade manuka honey (Medihoney) when used together with rifampicin, not only improved the efficacy of the antibiotic but also inhibit methicillin-resistant Staphylococcus aureus(MRSA) and rifampicin-resistant $S$. aureus in vitro $[24,26]$.

In the present experiment, raw honey showed greater zone of inhibition when compared to commercial honeys when applied with antibiotic (methicillin) or used as a sole agent. To find out if honey showed a synergistic effect when applied with methicillin, antibiotic discs were soaked in $100 \%$ honey solution and the results showed that the efficacy of methicillin increased when it was soaked in honey. Increased sensitivity to both antibiotics and Bangladeshi honeys were demonstrated in this study when they are used in combination, even when strains are clinically resistant to a particular antibiotic (methicillin); however, this depends on the antibiotic and on the $S$. aureus strain. This result clearly showed that honey can be used with a combination of antibiotics to increase its (antibiotic) efficacy.

\section{Conclusion}

Combinational treatment of honey and common antibiotics may offer a wide range of advantages including synergistic enhancement of the antibacterial activity, reduction of the effective dose of the antibiotic, and reduction of the risk of antibiotic resistance. It can also be suggested observing the results that raw honey should be used rather than commercial ones in $S$. aureus related infections. Nonetheless, only three types of honey were investigated in this study, while more diverse location and origin based honey is needed to be investigated in order to enhance knowledge on bactericidal activity of Bangladeshi honey. Based on the current study, it can be concluded that Bangladeshi raw honey has the potential to be an export quality honey, similar to Medihoney, if a broad range of analyses on both nutritional and bactericidal properties are carried out. Last but not the least can open a new door to novel drug development.

\section{Acknowledgement}

We are grateful to Ibn sina hospital (Dhaka), Bashundhara eye hospital (Dhaka) and Apollo hospital (Dhaka) for providing 
us bacterial samples. A very special thanks to the honey gatherer of Sundarban forest, Khulna for providing us raw honey sample. We greatly appreciate North South University and Department of Biochemistry and Microbiology laboratory officials for continuous support. Also, thanks to Syeda Farhana Afroz and Dr. Muhammad Maqsud Hossain for support. There was no financial support acquired from any sources for conducting this study.

\section{Conflict of Interest}

Authors declare no conflict of interest.

\section{References}

1. Molan P (1992) The antibacterial activity of honey: 2. Variation in the potency of the antibacterial activity. Bee World 73(2): 59-76.

2. Molan PC (1992) The antibacterial activity of honey: 1 . The nature of the antibacterial activity. Bee World 73(1): 5-28

3. Kwakman P, te Velde A, de Boer L, Speijer D, Vandenbroucke Grauls C, et al. (2010) How honey kills bacteria. FASEB J 24(7): 2576-2582.

4. Merckoll P, Jonassen T, Vad M, Jeansson S, Melby K (2009) Bacteria, biofilm and honey: A study of the effects of honey on 'planktonic' and biofilm-embedded chronic wound bacteria. Scand J Infect Dis 41(5): 341-347.

5. Nassar H, Li M, Gregory R (2012) Effect of Honey on Streptococcus mutans Growth and Biofilm Formation. Appl Environ Microbiol 78(2): 536-540.

6. Camplin A, Maddocks S (2014) Manuka honey treatment of biofilms of Pseudomonas aeruginosa results in the emergence of isolates with increased honey resistance. Annals of Clinical Microbiology and Antimicrobials, 13(1): 19.

7. Lu J, Turnbull L, Burke CM, Liu M, Carter DA, et al. (2014) Manukatype honeys can eradicate biofilms produced by Staphylococcus aureus strains with different biofilm-forming abilities. PeerJ 2: e326

8. Hammond E, Donkor E, Brown C (2014) Biofilm formation of Clostridium difficile and susceptibility to Manuka Honey. BMC Complementary and Alternative Medicine 14(1): 329

9. Paulus HS Kwakman, Johannes PC Van den Akker, Ahmet Güçlü, Hamid Aslami, Jan M Binnekade, et al. (2008) Medical-Grade Honey Kills Antibiotic-Resistant Bacteria In Vitro and Eradicates Skin Colonization, Clin Infect Dis 46(11): 1677-1682

10. Truchado P, López Gálvez F, Gil M, Tomás-Barberán F, Allende A (2009) Quorum sensing inhibitory and antimicrobial activities of honeys and the relationship with individual phenolics. Food Chemistry,115(4): 1337-1344.

11. Lee J, Park J, Kim J, Neupane G, Cho M, et al. (2011) Low concentrations of honey reduce biofilm formation, quorum sensing, and virulence in Escherichia coliO157:H7. Biofouling, 27(10): 1095-1104.
12. Wang R, Starkey M, Hazan R, Rahme L (2012) Honey's Ability to Counter Bacterial Infections Arises from Both Bactericidal Compounds and QS Inhibition. Front Microbiol 3: 144

13. Bhatia R, Narain J (2010) The growing challenge of antimicrobial resistance in the south-east Asia Region - are we losing the battle? Indian J Med Res 132(5): 482-486.

14. Masalha M, Borovok I, Schreiber R, Aharonowitz Y, Cohen G (2001) Analysis of Transcription of the Staphylococcus aureus Aerobic Class Ib and Anaerobic Class III Ribonucleotide Reductase Genes in Response to Oxygen. J Bacteriol (24): 7260-7272.

15. Huang H, Flynn N, King J, Monchaud C, Morita M, et al. (2006) Comparisons of Community-Associated Methicillin-Resistant Staphylococcus aureus (MRSA) and Hospital-Associated MSRA Infections in Sacramento, California. J Clin Microbiol 44(7): 2423-2427.

16. Chapman G (1945) The significance of sodium chloride in studies of staphylococci. J Bacteriol 50: 201-203.

17. Bauer AW, Kirby WM, Sherris JC, Turck M (1966) Antibiotic susceptibility testing by a standardized single disk method. Am J Clin Pathol 45(4): 493-496.

18. Phosphate buffered saline. Protocols Online.

19. Acharya T Mannitol Salt Agar (MSA): Composition, uses and colony characteristics - microbeonline [Internet]. microbeonline.

20. Bollela V, Sato D, Fonseca B (1999) McFarland nephelometer as a simple method to estimate the sensitivity of the polymerase chain reaction using Mycobacterium tuberculosis as a research tool. Braz J Med Biol Res 32(9): 1073-1076.

21. Natarajan S, Williamson D, Grey J, Harding K, Cooper R (2001) Healing of an MRSA-colonized, hydroxyurea-induced leg ulcer with honey. J Dermatolog Treat 12(1): 33-36.

22. Maeda Y, Loughrey A, Earle J, Millar B, Rao J, et al. (2008) Antibacterial activity of honey against community-associated methicillin-resistant Staphylococcus aureus (CA-MRSA). Complement Ther Clin Pract 14(2): 77-82.

23. Brudzynski K, Lannigan R (2012) Mechanism of Honey Bacteriostatic Action Against MRSA and VRE Involves Hydroxyl Radicals Generated from Honey's Hydrogen Peroxide. Front Microbiol 3: 36.

24. Irish J, Blair S, Carter D (2011) The Antibacterial Activity of Honey Derived from Australian Flora. PLoS ONE, 6(3): e18229.

25. Estrada He. Evaluation of the antimicrobial action of honey against Staphylococcus aureus, Staphylococcus epidermidis, Pseudomonas aeruginosa, Escherichia col.

26. Müller P, Alber D, Turnbull L, Schlothauer R, Carter D, et al. (2013) Synergism between Medihoney and Rifampicin against MethicillinResistant Staphylococcus aureus (MRSA). PLoS ONE 8(2): e57679. 